\title{
Historia de los receptores
}

\section{Alfredo Jácome Roca}

Internista-Endocrinólogo, miembro honorario de la ACE y miembro de número de la Academia Nacional de Medicina, Bogotá.

Fecha de recepción: 6/07/2017

Fecha de aceptación: 10/07/2017

$\mathrm{U}$ n receptor celular — tal como se conoce hoy- es una estructura tangible y sofisticada, necesaria para la acción de los ligandos. Gracias a ellos, se llevan a cabo los procesos bioquímicos que ponen en marcha la maquinaria genética y, en última instancia, la vida ${ }^{(1)}$.

Hace un siglo, dos científicos habían sugerido su presencia, aunque de manera un tanto nebulosa. Con el escepticismo incluso de los más sabios, el creciente conocimiento de la función del sistema nervioso neurovegetativo (en particular el adrenérgico), fue reforzando la "teoría del receptor", un concepto farmacológico que pasó del terreno de la hipótesis a un conocimiento detallado y real ${ }^{(2)}$.

La "teoría del receptor" explica el mecanismo de la activación del receptor y describe modelos para explicar las acciones de un fármaco. Hasta ahora, casi todos los modelos teóricos cuantitativos de función de receptores se han centrado en los canales de intercambio iónico y los receptores acoplados a proteínas $\mathrm{G}^{(3,4)}$.

Su contraparte, el ligando (que puede ser una hormona o un neurotransmisor), es no solo de importancia farmacológica sino lógicamente neuroendocrina. Fármacos y hormonas nuevas, se buscan a través de los receptores. Los que no tienen un ligando natural conocido (receptores huérfanos), son de gran interés investigativo $^{(2)}$.

\section{Las sustancias receptoras de Langley}

Al comenzar el siglo XX, el fisiólogo de Cambridge John Newport Langley ${ }^{(5,6)}$, fue quien primero propuso la teoría de los receptores, al explicar la acción de los alcaloides: "En todas las células se distinguen al menos dos constituyentes, una sustancia principal, que se ocupa de la función principal de la célula como contracción y secreción, y sustancias receptoras que son activadas por cuerpos químicos y en ciertos casos, por estímulos nerviosos. La sustancia receptora afecta o es capaz de afectar el metabolismo de la sustancia principal".

\section{Las "balas mágicas" de Ehrlich}

Paul Ehrlich (1854-1915) fue un eminente científico alemán nacido en Silesia (provincia de Prusia oriental, ahora Polonia), y es considerado el padre de la inmunología. Fue compañero de investigaciones de Behring y de Koch en temas de bacteriología, química, infectología, farmacología e inmunología, por lo que fue laureado con un premio Nobel.

Cuando investigaba sobre toxinas bacterianas, postuló que las células del organismo contenían estructuras que se combinarían con productos metabólicos de ciertas bacterias, lesionando dichas células. Aunque él no mencionó específicamente la palabra "receptores", consideraba dichas estructuras como cadenas laterales químicas "insatisfechas", concepto no lejano del actual, la de receptores como dominios presentes en enzimas y otras proteínas celulares con las que medicamentos, hormonas, y diversas biomoléculas de estructura específica pueden combinarse ${ }^{(7,8)}$.

Su investigación en quimioterapia la hizo basado en la idea (implícita en su tesis de grado), de que la constitución química de los medicamentos analizados debía estudiarse en relación con su modo de acción y su afinidad por las células de los organismos contra las que éstos se dirigían. Estas serían "balas mágicas" (que atacarían tejidos patológicos sin lesionar los sanos), al estilo de las antitoxinas que bloquean las toxinas, como cuando una llave encaja en una cerradura, analogía conceptual que se enseña cuando se habla de antígenos y de anticuerpos. Su concepto de receptor fue inicialmente farmacológico, pero luego lo cambió para dar cabida al inmunológico.

Muchas décadas más tarde, en investigaciones en las que participó el argentino César Milstein, se desarrollaron los anticuerpos monoclonales, ahora representados en fármacos biotecnológicos modernos.

A pesar del rigor de los estudios tanto de Ehrlich como de Langley, muchos no aceptaron el concepto de "receptor" para explicar la acción de los fármacos. Incluso el Nobel H.H. Dale (1875-1968), favoreció la capacidad distributiva sobre la interactividad de los medicamentos para determinar la selectividad sobre una célula efectora ${ }^{(9)}$. Clark fue el primero en cuantificar las respuestas biológicas inducidas por drogas ${ }^{(7)}$.

\section{Descubrimiento de la Epinefrina}

La epinefrina sería fundamental para el descubrimiento y estudio posterior de receptores. George Oliver y Edward Schäfer mostraron que un preparado a base de médula suprarrenal tenía un profundo efecto sobre la presión arterial ${ }^{(2,10)}$. En 1897, el farmacólogo americano John Jacob Abel (1857-1938), a partir de extractos de suprarrenales, aisló una sal pura de su principio activo (sulfato de adrenalina), primer producto que 
logró purificarse de una glándula endocrina ${ }^{(7)}$. Jokichi Takamine y Thomas Bell Aldrich, de manera independiente, cristalizaron la epinefrina y luego Ernst Friedmann reveló su estructura química. En cuanto a la prioridad del descubrimiento de la epinefrina, se entabló una lucha entre los laboratorios de Abel, Takamine e incluso Aldrich, por lo que en algún momento el Índice Merck listaba treinta y ocho términos diferentes para referirse a la misma sustancia: además de epinefrina (USP), adrenalina (BP), takamina, supracapsulina o adrenalina que fue la marca del compuesto de Parke \& Davis y que usa como si se tratara de un genérico ${ }^{(7)}$.

\section{La "simpatina" de Cannon}

Walter Bradford Cannon (1871-1945) contribuyó al conocimiento de cómo la médula suprarrenal contribuye al mantenimiento de la homeostasis durante un estado de estrés, concepto que se debe a uno de sus discípulos, el canadiense Hans Selye (1907-1982). En 1933, mientras hacía estudios sobre el sistema nervioso simpático tratando de comprobar la teoría de la lucha o la huida, concluyó que existían dos transmisores químicos que denominó simpatina E, para respuestas excitatorias; y simpatina I, para las inhibitorias ${ }^{(11)}$.

\section{La bioquímica del metabolismo intermediario}

Buena parte del conocimiento endocrino pionero se obtuvo antes de la segunda guerra mundial. En las nuevas teorías influyó el desarrollo de la bioquímica en esta época, cuando se descubrieron muchas enzimas del metabolismo intermediario. La glucólisis hepática y muscular, parte importante de la utilización de la glucosa, el metabolismo del ácido láctico, la síntesis de glucógeno y la neoglucogénesis, serían materia de estudio de Embden, Meyerhoff, Parnas, y de los esposos Cori $^{(2)}$. Vendría el descubrimiento del ciclo de Krebs (o de los ácidos tricarboxílicos) en las mitocondrias, responsables de la fosforilación oxidativa y de la generación de ésteres fosfóricos de alta energía como el adenosín trifosfato, o ATP. Houssay descubriría el efecto hiperglucemiante de la hipófisis anterior ${ }^{(12)}$. Varios de estos fisiólogos y bioquímicos recibieron el premio Nobel.

\section{Hormonas y sus mecanismos de acción}

En los años 20 se creía que hormonas y vitaminas tenían un mecanismo único de acción, que era directa sobre las enzimas. Se mezclaba una hormona dada con tejidos aislados, células homogeneizadas o preparaciones de partes de ellas, investigación que se facilitó con el advenimiento de enzimas purificadas. La interacción induciría cambios alostéricos o en la conformación de las proteínas ${ }^{(2)}$.

La insulina fue una hormona proteínica muy estudiada en su acción y su mecanismo, no solo porque fue una de las primeras hormonas descubiertas sino porque la bioquímica del me- tabolismo intermediario fue desarrollada en la primera mitad del siglo XX. Como, a principios de los años 40, Rachmiel Levine había propuesto que el control del metabolismo de los azúcares por parte de la insulina se debía a que ésta regulaba su transporte hacia el interior de la célula, empezó a considerarse que las señales proteínicas y de pequeños péptidos interactuaban con la membrana celular.

Dos farmacólogos, Brown y Gillespie, dedujeron en 1957, que en las terminaciones nerviosas debían existir receptores para la norepinefrina.

\section{Los receptores adrenérgicos de Ahlquist}

La terapéutica, que por siglos estuvo basada en plantas medicinales, dio un salto adelante con el descubrimiento de los alcaloides, las sustancias en ellas contenidas responsables de su eficacia sanadora. Las nuevas tecnologías permitieron encontrar que moléculas de tipo adrenérgico (epinefrina, norepinefrina y sus análogos) actúan en tejidos que contienen receptores tipo alfa y beta, según el sueco Raymond Alquist lo postuló en 1948(13,14).

Dichos receptores podían ser estimulados por moléculas agonistas y bloqueados por las antagonistas; se desarrollaron también conceptos de selectividad o especificidad. Se observarían fenómenos como la taquifilaxia (necesidad de más cantidad de medicamento para obtener el mismo resultado) y las regulaciones "hacia abajo" y "hacia arriba", que determinarían la sensibilidad o la resistencia de la molécula.

Este revolucionario aporte no fue uniformemente aceptado; el mismo Alquist dijo que se trataba de un "concepto". Así, muchos consideraron que la diferente respuesta adrenérgica se podía definir por la potencia del agonista. Para determinar que la respuesta se relacionaba con la ocupación de los receptores y la afinidad del agonista, se utilizó un modelo artificial en el que el uso de antagonistas atenuaba la respuesta agonista ${ }^{(13,14)}$.

La resistencia a aceptar el concepto de los receptores se debió, según Black ${ }^{(15)}$, a que el término "receptor" se había venido usando de una manera muy general. Se hablaba por ejemplo de osmorreceptores, quimiorreceptores, receptores sensoriales, etc. Pero no de receptores interactivos con fármacos o con hormonas.

\section{Los segundos mensajeros}

Earl Wilbur Sutherland (1915-1974) nació en Kansas. En aquellas épocas de la preguerra no era usual que los jóvenes ingresaran a la universidad. Sutherland sí lo hizo, en el Washburn College de Topeka, Kansas, donde también se encuentra el famoso centro de psiquiatría, la fundación Menninger. Un poco más al este, está la ciudad de Saint Louis, Missouri, donde Sutherland estudió medicina en la Universidad de Washington. Como estudiante, fue un aventajado alumno de Carl Cori y su esposa Gerty T. Cori-Radnitz en su laboratorio de la universidad, pareja que en 1947 recibiría el Premio Nobel de Fisiología y Medicina (junto con Houssay), por el descubrimiento de la con- 
versión catalítica del glucógeno. Allí, con sus tutores, el joven Sutherland estudió los efectos de la adrenalina y del glucagón en la conversión del glucógeno en glucosa (glucogenólisis); pero en 1942 debió hacer su internado en el Barnes Hospital de la misma universidad, y luego fue asignado a un hospital militar en Alemania, como médico de planta por tres años.

Lo suyo, sin embargo, era la investigación; regresó entonces, en 1945, al laboratorio de los esposos Cori en su Alma Mater. Reanudó sus investigaciones como instructor de farmacología y luego de bioquímica, hasta retirarse en 1953 como Profesor Asociado. Ese año se trasladó a Case Western Reserve University en Cleveland, Ohio, como Profesor y Jefe de Farmacología. Este hecho fue afortunado, porque allí encontró a Theodore W. Rall, con quien, por años, haría las investigaciones que lo llevarían al descubrimiento del adenosín monofosfato cíclico (AMPc) y su identificación como un segundo mensajero en la acción de ambas hormonas glucogenolíticas. Se trataba de una antigua molécula generada en diferentes tipos de células, ante la acción de señales hormonales y de otras extracelulares. A través del AMPc, se regulaban una serie de funciones celulares y procesos metabólicos tales como la lipólisis, la glucogenólisis, la secreción hormonal, la permeabilidad de los canales de intercambio iónico, la expresión genética, la proliferación y la supervivencia celulares. Estos trabajos, y el posterior descubrimiento de la enzima adenilciclasa, dieron pie al desarrollo moderno de la señalización intracelular ${ }^{(16-19)}$. Sutherland recibió el premio Nobel de Fisiología o Medicina en 1971.

Más adelante, se descubrieron otros segundos mensajeros: el 3',5'-GMP cíclico, el 1,2-diacilglucerol (DAG), el Inositol 1,4,5-trifosfato $\left(\mathrm{IP}_{3}\right)$, el calcio $\left(\mathrm{Ca}^{2+}\right)$, los fosfoinosítidos, y el gas óxido nítrico (NO), activado a través de los receptores de PTH/ PTHrP y mediado por el canal de calcio y de calmodulina (Ver Nobel de 1988).

Posteriormente, se encontró que otras hormonas proteínicas y liposolubles, que no podían ingresar a la célula a través de la membrana, también interactuaban con receptores transmembrana que, internamente, generaban un segundo mensajero. Entre éstas estaban la insulina, el factor de crecimiento epidérmico, la hormona del crecimiento y la prolactina, las hormonas hipotalámicas e hipofisiarias, la PTH y la calcitonina, además de varios neurotransmisores. Muchos de ellos están íntimamente ligados a la adenilciclasa y a las proteínas $\mathrm{G}$ y, a través de ellas, a las fosfocinasas proteínicas del citoplasma, que transfieren estas señales extracelulares a la maquinaria reguladora intracelular.

\section{Receptores de LDL}

En 1985, a Joseph L. Goldstein y Michael S. Brown les tocó el turno del Nobel cuando descubrieron el receptor de lipoproteínas de baja densidad y la regulación metabólica del colesterol, hallazgo que dio lugar a la obtención de moléculas hipolipemiantes, que conocemos genéricamente con el término de "estatinas"(20).

\section{Black y sus dos fármacos pioneros}

En 1988, George H. Hitchings, Sir James Black y Gertrude Elion recibieron el lauro del Instituto Karolinska por investigar principios importantes para el tratamiento con drogas, dirigidos a los receptores de membrana acoplados a proteínas $\mathrm{G}^{(21,22)}$. Dos fármacos que fueron luego muy usados -el propanolol y la cimetidina- se obtuvieron gracias al trabajo de Black. Los $\beta$-bloqueadores se volvieron populares en el tratamiento de la angina pectoris, la hipertension, las arritmias y el posinfarto del miocardio, este último uso confirmado por el estudio "BetaBlocker Heart Attack Trial (BHAT)".

\section{Neurofarmacología y neurofisiología}

Para no expandirnos en este tema, incluimos la lista de los premiados por la Academia Sueca en Estocolmo:

- 1970. Julius Axelrod, Bernard Katz y Ulf von Euler (Liberación y recaptación de neurotransmisores).

- 1991. Erwin Neher y Bert Sakmann (Función de los canales de intercambio iónico)

- 2000. Eric Kandel, Arvid Carlsson y Paul Greengard (Neurotransmisores como la dopamina, que actúan a través de los GPCR).

- 2004. Richard Axel y Linda B. Buck (Receptores olfativos acoplados a proteína G).

Otros premios Nobel relacionados con señalización y receptores fueron:

- 1986. Rita Levi-Montalcini y Stanley Cohen (factores de crecimiento, señalización)

- 1992. Edwin G. Krebs y Edmond H. Fischer (La fosforilación reversible funciona como un interruptor para activar las proteínas y para regular varios procesos celulares, incluyendo la glucogenólisis).

- 1998. Ferid Murad, Robert F. Furchgott y Louis J. Ignarro (Análisis del mecanismo de acción de agentes vasodilatadores y producción de óxido nítrico (NO), que afecta a las células musculares lisas). El NO es un gas que actúa como segundo mensajero en la acción de la PTH

\section{Receptores nucleares}

En 1961, Elwood Jensen y colaboradores, siguieron la pista del estradiol- $17 \beta$ radiomarcado en los tejidos sexuales femeninos, encontrando que forma un complejo con una proteína nuclear que llenaba los criterios para considerarse un receptor. Los receptores para esteroides y para las hormonas tiroideas pudieron ser clonados en varios laboratorios en la década de los $80^{(23-25)}$.

\section{Las proteínas G de Gilman y Rodbell}

Cuando Alfred G. Gilman y Martin Rodbell investigaron la estimulación celular por la epinefrina, encontraron que, al fijarse al receptor, la hormona no estimulaba enzimas directamen- 
te; este estímulo enzimático lo hacía a través de unas proteínas acopladas al receptor, que eran responsables de la activación por la guanina trifosfato (GTP), por lo que las llamaron proteínas G. Este complejo llamado "receptores acoplados a proteínas G (GPCR)" es una superfamilia de receptores 7 transmembrana (figura 1). Éstas entonces estimulan la adenilciclasa, que a su vez producen el AMPc como segundo mensajero. Así, les correspondió recibir el Nobel en 1994, por el papel de dichas proteínas en la transducción celular de las señales ${ }^{(26-28)}$.

\section{Receptores identificados por fijación de ligandos radiactivos}

La identificación directa de los receptores biológicos se logró con el uso de radioligandos que conservaban su actividad después de ser yodados o tritiados. Esto permitió una explosiva caracterización de muchos receptores, siendo el primero el del ACTH yodada. En 2012, Brian Kobilka y Robert Lefkowitz recibieron el Nobel de Química por aportar datos completos sobre la función de los GPCR ${ }^{(29-32)}$. Peter G. Waser dio a conocer el receptor de membrana para la acetilcolina, usando la autorradiografía $^{(33)}$. En 1973, Pert y Snyder publicaron el primer estudio con radioligandos, que permitió el descubrimiento de un receptor de opioides, al usar la naloxona $\mathrm{H}^{3(34)}$.

\section{Enfermedad y receptores}

Un clínico, Fuller Albright (1900-1969), describió el pseudohipoparatiroidismo (osteodistrofia hereditaria) en 1942, debido a resistencia a la parathormona (cuyo receptor hormonal se descubrió posteriormente). En el hiperparatiroidismo secun-
Figura 1. Receptor transmembrana, ligado a proteína G

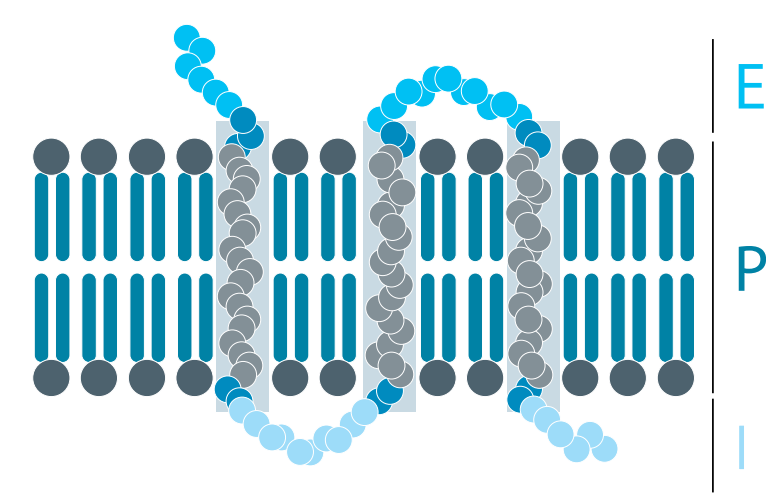

E: Porción extracelular. P: membrana plasmática. I: Porción intracelular

dario a la falla renal y en el síndrome de Klinefelter (también estudiados por Albrigth), la falla se presenta en las células efectoras, impidiendo la acción de la hormona. Este investigador de Boston fue el clásico ejemplo de la unión entre la endocrinología clínica y la molecular ${ }^{(2)}$.

La clonación molecular y la verificación de secuencias, también proporcionaron la base para asignar las correspondientes alteraciones moleculares en la enfermedad. La endocrinología, al principio, se enfocó en enfermedades causadas por alteraciones en la disponibilidad de "agonistas" hormonales (hiper o hipo); pero luego, los conocimientos moleculares sobre la señalización de receptores han permitido conocer la relación causal entre el genotipo y el fenotipo, y la contribución de las modulaciones postranscripcionales y postraduccionales en la patología endocrina.

\section{Referencias}

1. Lizcano F, Duque JJ. Hormonas, receptores y control endocrino. En: Fisiología Endocrina, 4a a Edición (Alfredo Jácome Enrique Ardila Luz A Casas, Eds). Editorial Manual Moderno, Bogotá, 2017.

2. Jácome-Roca A. Historia de las Hormonas. Academia Nacional de Medicina, 2008. Pp.

3. Rang HP (2006). "The receptor concept: pharmacology's big idea”. Br. J. Pharmacol. 147 (S1): S9-16.

4. Limbird LE (2004). “The receptor concept: a continuing evolution”. Mol. Interv. 4 (6): 32636.

5. Langley, J.N. On the contraction of muscle, chiefly in relation to the presence of "receptive" substances. Part IV. The effect of curare and of some other substances on the nicotine response of the sartorius and gastrocnemius muscles of the frog. J. Physiol. 1909; 39, 235295

6. Maehle AH: 'Receptive substances': John Newport Langley (1852-1925) and his path to a receptor theory of drug action. Med Hist 2004; 48:153-174

7. Jácome-Roca A. Historia de los Medicamentos. Academia Nacional de Medicina. 2003. Pp.

8. Erhlich P. Chemotherapeutics: Scientific principles, methods and results. Lancet 1913; 2 , 445-451.

9. Dale HH. The action of certain esters and ethers of choline, and their relation to muscarine. J. Pharm. Exp. Ther. 1914; 6, 174-190

10. Sneader W. The discovery and synthesis of epinephrine. Drug News Perspect. 2001;14 (8):491-4.

11. Cannon WB, Rosenbueth A. Studies on the conditions of activity in endocrine organs: XXIX. Sympathin E and sympathin I. Am J Physiol 104: 557-574, 1933.

12. Jácome-Roca A. Houssay, Leloir y los nóbeles latinoamericanos de ciencias. Rev Col Endocrinol Diab Metab 2017; 4 (1): 34-39.

13. Ahlquist, R.P. A study of the adrenotropic receptors. Am. J. Physiol. 155, 586-600 (1948).

14. Ahlquist, R.P. Historical perspective. Classification of adrenoreceptors. J. Auton. Pharmacol 1,101-106(1980).

15. Black JW, Leff P. Operational Models of Pharmacological Agonism. Proc R Soc London Ser. B 1983; 220: 141-162.

16. Blumenthal SA. Earl Sutherland (1915-1974) and the discovery of cyclic AMP. Perspect Bio Med. 2012; 55(2):236-49.
17. Earl W. Sutherland, Jr. Facts. Nobelprize.org. Nobel Media AB 2014. Web. 19 Jun 2017.

18. Furchgott RF. The receptors for epinephrine and norepinephrine (adrenergic receptors) Pharmacol Rev 11: 429-441, 1959.

19. Stephenson, R.P. A modification of receptor theory. Br. J. Pharm. 11, 379-393 (1956).

20. Nair P. Brown and Goldstein: The Cholesterol Chronicles. PNAS 2013; 110 (37): 14829 14832

21. Stapleton MP: Sir James Black and propranolol: the role of the basic sciences in the history of cardiovascular pharmacology. Tex Heart Inst I 1997;24:336-34.

22. Quirke V (2006). "Putting theory into practice: James Black, receptor theory and the development of the beta-blockers at ICI, 1958-1978". Med Hist. 50 (1): 69-92.

23. Mangelsdorf DJ et al. The nuclear receptor superfamily: the second decade. Cell 1995; 83 835-839.

24. Benoit G, Malewicz M, Perlmann T. Digging deep into the pockets of orphan nuclear receptors: insights from structural studies. Trends Cell Biol 2004;14: 369-376.

25. Aranda A, Pascual A. Nuclear hormone receptors and gene expression. Physiol Rev. 2001 81 (3): 1269-1304.

26. Lefkowitz R. Historical review: A brief history and personal retrospective of seven-transmembrane receptors. Trends Pharm. Sci. 2004; 25: 413-422.

27. Rodbell M, Birnbaumer L, Pohl SL, Krans HM. The glucagon- sensitive adenyl cyclase system in plasma membranes of rat liver. $V$. An obligatory role of guanylnucleotides in glucagon action. J. Biol. Chem. 1971; 246, 1877-1882 (1971).

28. Gilman AG. G proteins: Transducers of receptor generated signals. Annu. Rev. Biochem $1987 ; 56,615-649$.

29. Lefkowitz RJ, Roth J, Pricer W, Pastan I. ACTH receptors in the adrenal: Specific binding of ACTH-1251 and its relation to adenyl cyclase. Proc. Natl. Acad. Sci. U.S.A. 65, 745-752 (1970).

30. Kobilka, B.K. Agonist binding: A multi-step process. Mol. Pharm. 65, 1060-1062 (2004).

31. Tata JR. One hundred years of hormones. EMBO Rep. 2005; 6(6): 490-496.

32. Limbird LE: The receptor concept: a continuing evolution. Mol Interv 2004; 4:326-336.

33. Waser PG. Autoradiography of End-plates with Carbon-14). Nature, 1956:;178 (4540): 981.

34. Pert CB, Snyder SH. Opiate receptor: demonstration in nervous tissue. Science 1973; 179 (4077): 1011-4 